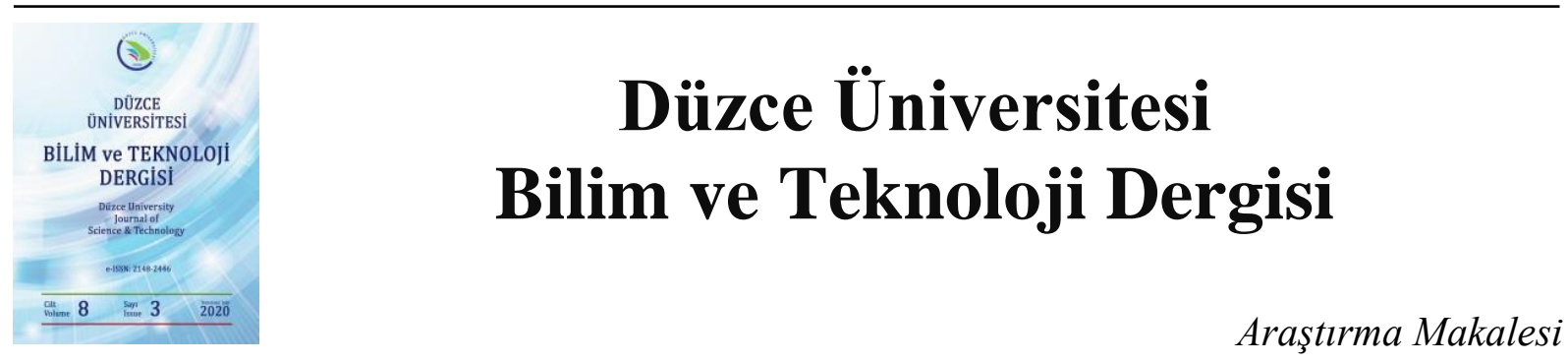

\section{Davlumbazlarda Kullanılan Komponent Özelliklerinin Enerji Tüketimi ve Çalışma Performansı Üzerine Etkisinin Deneysel- İstatiksel Olarak İncelenmesi}

\author{
(1)Yusuf ÖZBAKIŞ ${ }^{\mathrm{a}, *}$, DEngin NAS ${ }^{\mathrm{b}}$ \\ ${ }^{a}$ Makine Mühendisliği Bölümü, Mühendislik Fakültesi, Düzce Üniversitesi, Düzce, TÜRKIYE \\ ${ }^{b}$ Makine ve Metal Teknolojileri Bölümü, Cumayeri Meslek Yüksek Okulu, Düzce Üniversitesi, Düzce, TÜRKiYE \\ * Sorumlu yazarın e-posta adresi: yusufozbakis@hotmail.com
}

DOİ: 10.29130/dubited.716394

\begin{abstract}
ÖZET
$\mathrm{Bu}$ çalışmada mutfak davlumbazlarında kullanılan, motor ve filtrelerin ürün performans ve enerji tüketimi üzerine etkileri deneysel ve istatiksel olarak incelenmiştir. Bu amaç için mutfaklarda kullanılan iki farklı boyuta sahip piramit tipi, davlumbaz seçilmiştir. Deneylerin gerçekleştirilmesi için iki farklı boyutta $(60-90 \mathrm{~cm})$ gövde, iki farklı özellikte motor $\left(450-650 \mathrm{~m}^{3} / \mathrm{h}\right.$ ) ve iki tip filtre (3-5 katman) konfigürasyonuna sahip davlumbazların üretimi yapılmıştır. Çalışmanın deneysel tasarımı Taguchi $\mathrm{L}_{8}$ dizilimi kullanılarak oluşturulmuş ve deneyler gerçekleştirilmiştir. Deney sonuçları incelendiğinde, $60 \mathrm{~cm}$ boyuta sahip davlumbazların yıllık enerji tüketimi (AEC) en düşük 43,6 kWh iken en yüksek 62,7 kWh olduğu ve $90 \mathrm{~cm}$ boyuta sahip davlumbazların ise en düşük $48,7 \mathrm{kWh}$ iken en yüksek $63,0 \mathrm{kWh}$ olduğu görülmüsstür. Filtrelerin yağ tutma verimliliği incelendiğinde en düşük yağ filtre verimliliği $\% 68,4$ olarak $90 \mathrm{~cm}$ boyuta sahip davlumbazda ve en yüksek $\% 80,6$ olarak $60 \mathrm{~cm}$ boyuta sahip davlumbazda oluşmuştur. Deneysel sonuçların istatiksel olarak incelenmesinde Sinyal/Gürültü oranları, Anova ve Regresyon analizleri kullanılmıștır. Sinyal/Gürültü oranları incelendiğinde en verimli noktadaki debi $\left(\mathrm{Q}_{\mathrm{BEP}}\right.$ ), yıllık enerji tüketimi (AEC), maksimum devirde hava akışı, gürültü performansı $\left(\mathrm{L}_{\mathrm{WA}}\right)$ ve yağ filtresi verimliliği $\left(G_{F E}\right)$ için en ideal seviyeler sırası ile $A_{2} B_{2} C_{2}, A_{1} B_{1} C_{2}, A_{2} B_{2} C_{2}, A_{2} B_{2} C_{1}$ ve $A_{1} B_{2} C_{1}$ olarak belirlenmiştir. Anova sonuçları incelendiğinde $\mathrm{Q}_{\mathrm{BEP}}$, AEC, maksimum devirde hava akışı ve $\mathrm{L}_{\mathrm{WA}}$ için en etkili parametrenin surası ile $\% 96,62, \% 93.02, \% 98,87, \% 41,45$ oranla motor , yağ filtresi verimliliği için en etkili parametrenin ise $\% 62,72$ oranla filtre katmanı olduğu tespit edilmiştir.
\end{abstract}

Anahtar Kelimeler: Konfigürasyon, Optimizasyon, Havalandırma, Davlumbaz

\section{Experimental-Statistical Analysis of the Effect of Component Properties Used in Hoods on Energy Consumption and Operating Performance}

\begin{abstract}
In this study, the effects of motors and filters used in kitchen hoods on product performance and energy consumption were investigated experimentally and statistically. For this purpose, two different
\end{abstract}


sizes of pyramid hoods used in kitchens were chosen. In order to carry out the experiments, hoods with two different sizes $(60-90 \mathrm{~cm})$ body, two different engine $(450-650 \mathrm{~m} 3 / \mathrm{h})$ and two types of filter (3-5 layers) configurations were produced. The experimental design of the study was created using the Taguchi L8 sequence and experiments were carried out. When the experiment results are examined, the annual energy consumption (AEC) of the $60 \mathrm{~cm}$ size hoods were found to be the lowest $43,6 \mathrm{kWh}$, the highest $62,7 \mathrm{kWh}$ and for the $90 \mathrm{~cm}$ size hoods were found to be the lowest $48.7 \mathrm{kWh}$ and the highest $63.0 \mathrm{kWh}$. When the grease retain efficiency of the filters was analyzed, it was observed that the lowest greas filter efficiency was in the $90 \mathrm{~cm}$ size hood with $68.4 \%$ and the highest greas filter efficiency was in the $60 \mathrm{~cm}$ size hood with $80.6 \%$. Signal / Noise ratios, Anova and Regression analyzes were used for statistical analysis of experimental results. When the signal / noise ratios are analyzed, the most ideal levels for flow rate (QBEP), annual energy consumption (AEC), maximum flow air flow, sound performance (LWA) and grease filter efficiency (GFE) are determined as $\mathrm{A} 2 \mathrm{~B} 2 \mathrm{C} 2, \mathrm{~A} 1 \mathrm{~B} 1 \mathrm{C} 2, \mathrm{~A} 2 \mathrm{~B} 2 \mathrm{C} 2, \mathrm{~A} 2 \mathrm{~B} 2 \mathrm{C} 1, \mathrm{~A} 1 \mathrm{~B} 2 \mathrm{C} 1$ respectively. When the Anova results are examined, the most effective parameters for QBEP, AEC, maximum speed air flow and LWA are determined as engines with $96.62 \%, 93.02 \%, 98.87 \%, 41.45 \%$, respectively, the most effective parameter for grease filter efficiency was determined as the filter layer with a rate of $62.72 \%$.

Keywords: Configuration, Optimization, Ventilation, Hood

\section{GIRISS}

Ülkelerin kalkınması o ülkenin sahip olduğu tüm yeraltı ve yerüstü kaynaklarını en verimli bir biçimde kullanılmasına bağlıdır. Bunu sağlarken de günümüzde çok hızlı bir ilerleme gösteren teknolojik gelişmelerin de gerisinde kalmaması gerekmektedir. Neticede bu konular rekabeti zorunlu hale getirmektedir. Rekabette de başarılı olabilmenin şartı, verimli üretim yapabilmektir.

Havalandırma sistemi, ortamdaki kirlenmiş havayı ortamdan çıkarırken ortama temiz havanın sokulması ve sirküle edilmesi işlemini gerçekleştirmektedir. Havalandırma sistemlerinin temel amacı, iç mekânlarda hava kalitesi ve termal konforu, ortamda bulunan insanlar için sağlik, rahatlık ve üretkenlik koşullarını dikkate alarak optimum koşulları oluşturmaktır [1].

Bugün çeşitli Avrupa ülkelerinde, çeşitli havalandırma stratejileri vardır. Genellikle bazı ülkelerde, kontrolsüz hava sızıntısı ve pencere açıklığı tek havalandırma iken, bazı ülkelerde havalandırma sistemleri kullanılmaktadır. Daha soğuk iklime sahip ülkelerde ise, sadece egzoz veya dengeli egzoz, 1S1 geri kazanım üniteleri veya mekanik sistemler kurulmuştur [2, 3].

Enerji rezervlerinin havalandırma oranları üzerindeki etkisi 1973 yılında Birleşik Devletlerde Arap Petrol Ambargosu ile başladı ve bu durumun ise enerji maliyetlerinin artış göstermesine ve dolayısıyla binaların 1sınmasındaki maliyetlerin artmasına neden olmuştur. Maliyetlerin artması ise binaların havalandırılmasının azalmasına sebep olmuştur. Son yıllarda havalandırma oranlarındaki azalma, sanayileşmiş ülkelerde astım prevalansını arttırmıştır. Bu durumda zamanla alerjik hastalıklardaki artışla örtüşmektedir $[4,5]$.

Endüstriyel ve sivil uygulamalar için kirli havaların yakalanmasında davlumbazlara olan ilgi son zamanlarda yeniden artmıştır. Davlumbazlar birçok uygulama alanında (kimya endüstrisi, gıda 
endüstrisi, endüstriyel depolar ve binalar v.b.) ortamdaki egzoz gazlarını, kirli veya kirletilmiş havayı ve nemli havayı ortamdan dişarı atmak için kullanılmaktadır [6].

Avrupa'da mutfak davlumbazları Avrupa Enerji Etiketleme Direktifi tarafından belirlenen enerji verimlilik sınıfları, enerji tüketimi ve gürültü seviyesi ile ilgili diğer bilgileri gösteren bir enerji etiketi ile birlikte gelmektedir. Son düzenlemeler nedeniyle davlumbaz tasarımları, enerji verimliliğinin değerlendirilmesi, enerji tüketiminin analizi ve ürün yaşam döngüsü etkisi gibi yeni konuları göz önünde bulundurularak yapılmaktadır. Bu nedenlerden dolayı, eko güdümlü ürünlerin geliştirilmesi, eko-yeniliği ve ilgili sürdürülebilirlik iyileştirmelerini desteklemek için Ecodesign araçlarınının kullanılmasını gerektirmektedir [7].

Sera gazı emisyonlarının azaltılmasında, davlumbaz enerji verimliliğinin arttırılması ve enerji tüketiminin genel olarak azaltılması önemli rol oynamaktadır [8]. Günümüzde, ürün enerji etiketleri dünya çapında, enerji tüketimi ile ilgili bilgi eksikliğine yanıt vermek için kullanılmakta olup insanların ürün satın alırken çevre bilinci, sosyal etkileşim ve eğitim düzeylerinin önemli etkileri olduğunu göstermektedir [9].

Literatür taraması yapıldığında ticari mutfak davlumbazı ve ev tipi mutfak davlumbazı ile ilgili birçok çalışma yapıldığı görülmektedir. Araştırmacılar genellikle bu çalışmalarda davlumbaz motoru ve davlumbaz tasarımı üzerine çalışmaktadır. Çalışmaların davlumbaz hava debisi ve enerji tüketimi üzerine olduğu görülmektedir [7, 10-13]. Literatürde davlumbazda kullanılan komponentlerinin ürün performansına (gürültü performansı ve yağ filtresi verimliliği) etkileri ile ilgili yeteri kadar çalışma olmadığı görülmüştür. Bu çalışmada, davlumbazlarda kullanılan komponentlerin ürün performansı (en verimli noktadaki debi, yıllık enerji tüketimi, maksimum devirde hava akışı, gürültü performansı ve yağ filtresi verimliliği) üzerindeki etkileri deneysel ve istatiksel olarak araştırılması amaçlanmıştır.

\section{MUTFAK DAVLUMBAZLARI İCIN ENERJI ETIKETI}

Son yıllarda, $\mathrm{AB}$ Ecodesign direktifi enerji bağlantılı ürünlerin enerji tüketimini ve çevresel etkilerini azaltmak zorunda olduğunu belirtmektedir [14]. AB Ecodesign direktifi (2009/125/EC), enerji kullanımı ve enerji ile bağlantılı ürünler için zorunlu ekolojik gerekliliklerini belirleyerek Enerji Etiketleme Direktifi (AB Direktifi 2010/30/EU, 2014/65/EU) ile bir çerçeve oluşturmuştur. Ecodesign ve enerji etiketlemesinin birleşimi, enerji verimliliği alanındaki en önemli gelişmelerden biri olmaktadır. Son yıllarda enerji tüketim yönetimi kapalı mekanlarda giderek daha önemli hale gelmektedir. Bu nedenle, 2015 yılından itibaren AB mevzuatı, mutfak davlumbazlarının üreticisine, nihai müşteriye cihazın enerji tüketimine ilişkin özellikleri gösteren bir enerji etiketi sağlamasını zorunlu kılmaktadır (Şekil 1) [15-16]. 


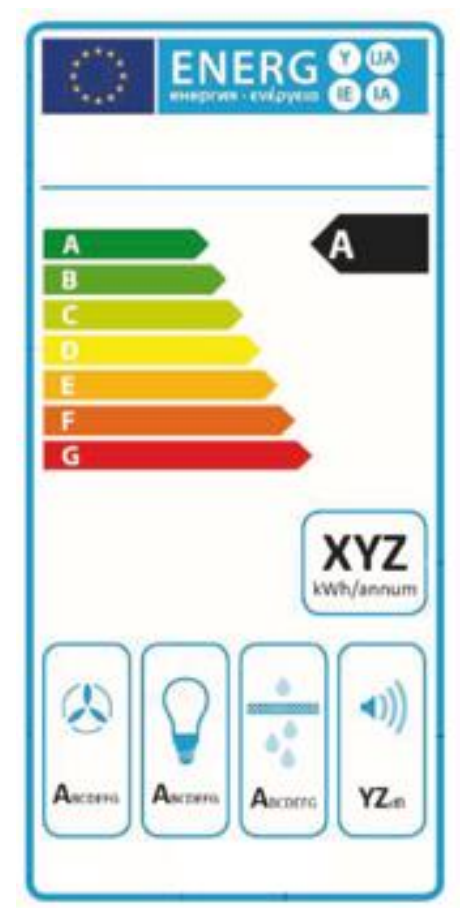

Şekil 1. Mutfak davlumbazları için enerji etiketi. [16]

Enerji verimlilik indeksi (EEI), davlumbazın yıllık enerji tüketimi (AEC) ile $\mathrm{kWh} / \mathrm{y} 1 \mathrm{l}$ olarak ifade edilen standart y1llık tüketim (SAEC) arasındaki oranı temsil eden A'dan G'ye kadar bir ölçek tanımlanmaktadır. Yönerge, Ocak 2015'te başlanarak, 2020 y1lına kadar her iki y1lda bir yeni enerji verimliliği sınıfı (A +, A ++ vb.) olacak şekilde hazırlanmaktadır [14]. Mutfak davlumbazları için ek verimlilik indeksleri: sıvı dinamiği verimliliği $(\mathrm{FDE})$, yağ filtrelemede verimlilik $\left(\mathrm{G}_{\mathrm{FE}}\right), \mathrm{dB}$ cinsinden ifade edilen akustik kirlilik seviyesidir. Enerji verimlilik endeksi aşağıdaki denklemde (Eşitlik 1) gösterildiği gibi yıllık enerji tüketimi ile standart yıllık tüketim arasındaki oran olarak tanımlanmaktadır [15]. Sıvı dinamik verimlilik indeksi, aşağıdaki denklemde (Eşitlik 2) gösterildiği gibi aspirasyon (hava çekiş) sisteminin faydalı etkisi ile elektrik tüketimi arasındaki oran olarak tanımlanmaktadır [16]. FDE'nin maksimuma ulaştığı çalışma noktasında $\mathrm{Q}_{B E P}\left(\mathrm{~m}^{3} / \mathrm{h}\right)$ en iyi verimlilik noktası hesaplanmaktadır. Ayrıca bu eşitlikte; $\mathrm{P}_{\mathrm{BEP}}(\mathrm{Pa})$ ilgili statik basınç değerini ve $\mathrm{W}_{\mathrm{BEP}}(\mathrm{W})$ elektrik güç tüketimini ifade etmektedir [15].

$$
\begin{aligned}
& \mathrm{EEI}=\frac{\mathrm{AEC}}{\mathrm{SAEC}} \times 100 \\
& \mathrm{FDE}=\frac{\mathrm{Q}_{\mathrm{BEP}} \cdot \mathrm{P}_{\mathrm{BEP}}}{\mathrm{w}_{\mathrm{BEP}} \cdot 3600} \times 100
\end{aligned}
$$

Yağ filtreleme $\left(\mathrm{G}_{\mathrm{FE}}\right)$ verimliliği, EI 61591 standardına göre Eşitlik 3'teki gibi hesaplanmaktadır. Buradaki hesaplamalarda kütle birimi gram olarak değerlendirilmektedir. $\mathrm{w}_{\mathrm{g}}(\mathrm{g})$ yağ filtresindeki yağın kütlesini, $\mathrm{w}_{\mathrm{t}}(\mathrm{g})$ mutlak filtredeki yağın kütlesini, $\mathrm{w}_{\mathrm{r}}(\mathrm{g})$ ürünün tuttuğu yağın kütlesini tarif etmektedir [17].

$$
\mathrm{G}_{\mathrm{FE}}=\frac{\mathrm{w}_{\mathrm{g}}}{\mathrm{w}_{\mathrm{r}}+\mathrm{w}_{\mathrm{t}}+\mathrm{w}_{\mathrm{g}}} \times 100
$$

Son olarak, üretilen gürültü seviyesi, uluslararası standart olan IEC 60704 standardına göre davlumbazın maksimum güçte olduğunda hesaplanmaktadır [18]. 
Yapılan bu çalışmada, mutfak davlumbazlarında kullanılan boyut, filtre ve motorların seçiminde performans değerlerinin optimizasyon çalışması yapılmıştır. Deney tasarımı Taguchi $\mathrm{L}_{8}$ ortogonal yöntemine göre oluşturulmuştur. Deneylerden elde edilen sonuçların sinyal/gürültü $(\mathrm{S} / \mathrm{N})$ oranı ve ANOVA analizleri gerçekleştirilerek ideal ürünün üretilebilmesi için parametrelerin belirlenmesi ve bu parametreler içinde en etkili parametrenin hangisi olduğuna karar verilmesi amaçlanmıştır. Regresyon analizleri ile oluşturulacak matematiksel model sayesinde aynı girdi parametreleri ile farklı değerlerde üretilecek davlumbazın çıktı sonuçlarının önceden tahmin ederek, enerji tüketimi ve zaman kaybının ortadan kaldırılması amaçlanmıştır.

\section{MATERYAL METOT}

Mutfaklarda pişirme esnasında yemeklerden çıkan 1sı, kirletici hava ve kirletici gazların tahliyesini optimal düzeyde sağlamak için mutfaklarda daha verimli ve daha yüksek performanslı davlumbazlar gerekmektedir. Son zamanlarda, mutfak davlumbazlarının havalandırma performansına ilgi artmaktadır [19]. Ortamdaki havanın filtrelenmesinde ve tahliye edilmesinde verimsiz bir sistem, pişirme alanında bulunan tüm kişilerin sağlığı için risk oluşturmaktadır [20]. Sera gazı emisyonlarının azaltılması için, davlumbaz enerji verimliliğinin artması ve enerji tüketiminin genel olarak azaltılması önemli rol oynamaktadır [8].

Davlumbazlarda enerji verimliliğinin artırılması ve enerji tüketiminin azaltılması, davlumbazda kullanılan komponentlerin doğru seçimi ile sağlanabilir. Bu çalışmada mutfak davlumbazlarının ebatı, motoru ve filtrelerinin ürün performans ve enerji tüketimi üzerine etkilerinin araştırılması amaçlanmıştır. $\mathrm{Bu}$ amaç için mutfaklarda kullanılan piramit tipi, iki farklı boyuta $(60 \mathrm{~cm}$ ve $90 \mathrm{~cm})$ sahip davlumbaz, 2 farklı motor ve 2 farklı filtre seçilmiştir. Davlumbazların performansını optimize etmek için Taguchi yönteminden yararlanılmıştır. Seçilen yöntem ile farklı özelliklerde ebat, motor ve filtre konfigürasyonuna sahip davlumbazlar oluşturulmuştur. Deneyde kullanılan ürün ve komponentler Şekil 2'de, ürün gövde ebatları Şekil 3’te gösterilmiştir.

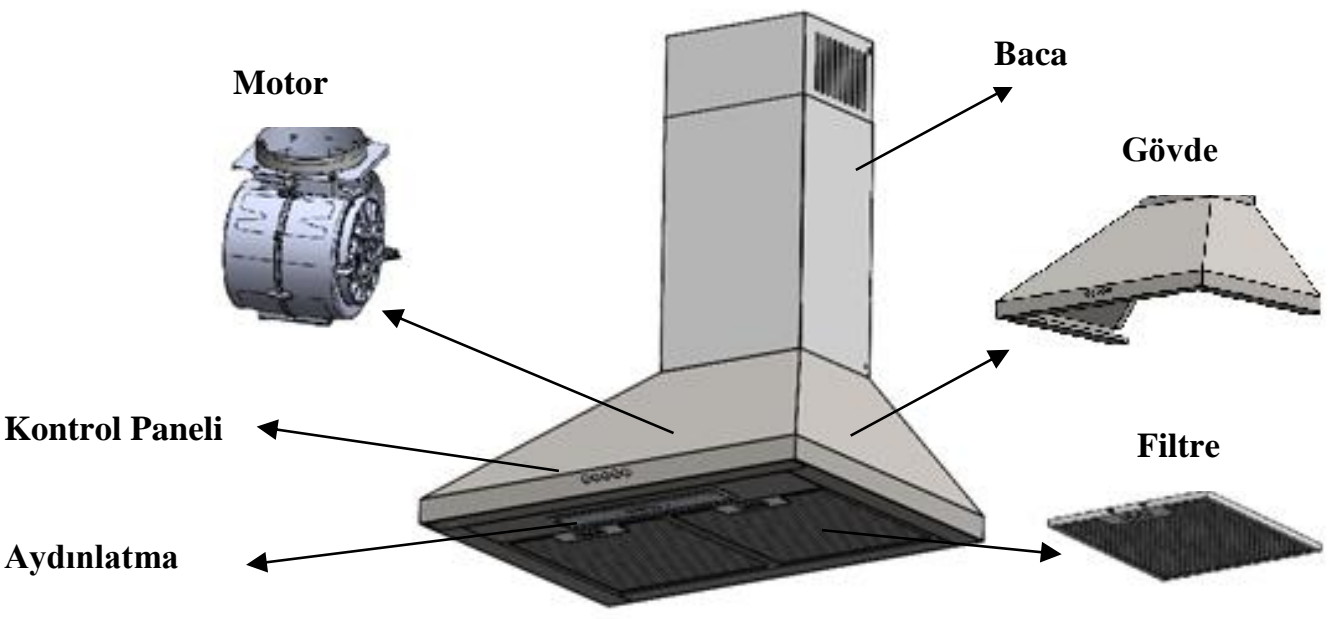

Şekil 2. Deneyde kullanılan davlumbaz ve komponentler. 


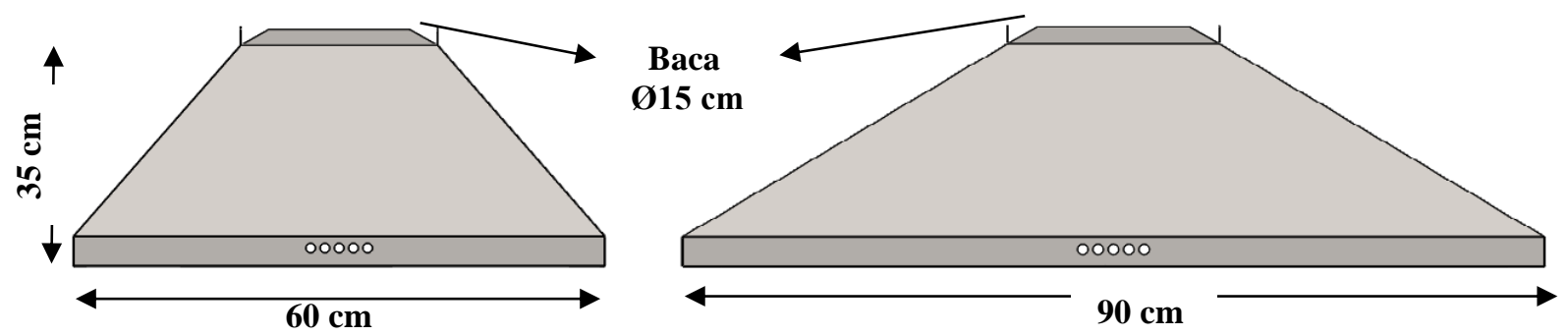

Şekil 3. Deneyde kullanılan davlumbaz gövde ebatları.

Seçilen 2 farklı boyuttaki ürün, iki farklı özelliğe sahip motor ve 2 farklı özellikte filtre ile deney tasarımının gerçekleştirilmesinde Taguchi $\mathrm{L}_{8}$ deney tasarımı yöntemi kullanılmıştır. Deney faktör ve seviye değerleri Tablo 1'de, deney tasarımı Tablo 2'de gösterilmiştir.

Tablo 1. Deneysel çalışmada kullanılan parametreler ve seviyeleri.

\begin{tabular}{lccc}
\hline \multirow{2}{*}{ Faktör } & \multicolumn{3}{c}{ Seviye } \\
\cline { 2 - 4 } & Kod & $\mathbf{1}$ & $\mathbf{2}$ \\
\hline Boyut $(\mathrm{cm})$ & A & 60 & 90 \\
Filtre $($ katman $)$ & B & 450 & 650 \\
Motor $\left(\mathrm{m}^{3} / \mathrm{h}\right)$ & C & 3 & 5
\end{tabular}

Tablo 2. Taguchi $L_{8}$ deney tasarımı

\begin{tabular}{cccc}
\hline \multicolumn{4}{c}{ Girdi Parametreleri } \\
\hline No & A & B & C \\
\hline 1 & 60 & 3 & 450 \\
2 & 60 & 3 & 650 \\
3 & 60 & 5 & 450 \\
4 & 60 & 5 & 650 \\
5 & 90 & 3 & 450 \\
6 & 90 & 3 & 650 \\
7 & 90 & 5 & 450 \\
8 & 90 & 5 & 650 \\
\hline
\end{tabular}

\section{A. HAVA AKIŞI VE PERFORMANS ÖLÇÜMÜ}

Davlumbazlar, pişirme alanındaki dumanı, buharı ve gazları ortamdan çıkarmak için basınç farkı oluştururlar [10]. Davlumbazların hava akış hızı ve basıncı açısından enerji tüketimini, enerji verimliliğini ve performansını ölçmek için test prosedürü uluslararası standart olan IEC 61591'de belirtilmiştir. Yapılan bu çalışmada tüm hava akış testleri, uluslararası standart olan IEC 61591 ile uyumlu ve sertifikalı makinelere sahip akredite test laboratuvarında yapılmıştır [17]. Deneylerde ILK Dresden marka hacimsel hava akış ve porformans ölçüm sistemine ait bazı özellikler Tablo 3'te verilmiştir. Deneysel testlere ait ürün, test düzeneği ve şematik resmi Şekil 4'te gösterilmiştir. 

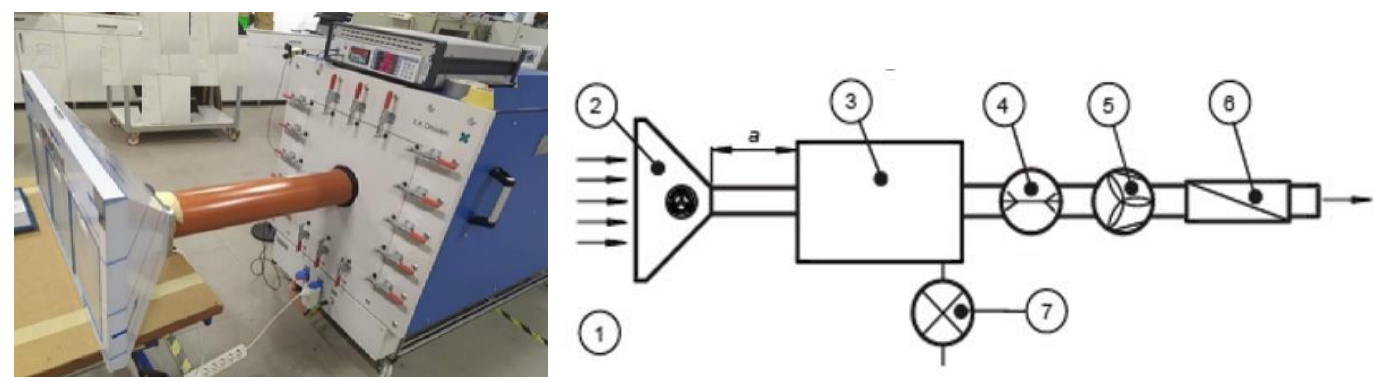

Şekil 4. Hacimsel hava akış ve performans testi ve şematik hali.

(1)Test odası, (2) Davlumbaz, (3) Basınç dengeleme haznesi, (4) Orifis(basınç farkı oluşumu için akıı̧ ağızı), (5) Yardımcı fan, (6) Baffle(bölme), (7) Statik basinç göstergesi

Farklı komponentler ile oluşturulan sekiz farklı davlumbazın deneyleri Şekil 4'te gösterilen uluslararası standartlara sahip test cihazında yapılmıştır. Ölçüm cihazlarının oluşturmuş olduğu bu grafiklerde ürünlere ait sıvı dinamik verimlilik (FDE), en verimli noktadaki debi $\left(\mathrm{Q}_{\mathrm{BEP}}\right)$, statik test basınç (Pa), şebekeden çekilen akım (A) ve şebeke gerilimi (V) değerleri gösterilmiştir.

Tablo 3. Hacimsel hava akış ve porformans ölçüm cihazı özellikleri.

\begin{tabular}{ll}
\hline Marka / Tip & ILK Dresden / ILK-B-31 \\
Test basınc1 / Çözünürlük & $-5 \mathrm{kPa}-5 \mathrm{kPa} / 0,1 \mathrm{~Pa}$ \\
Debi & $18 \mathrm{~m}^{3} / \mathrm{h}-2700 \mathrm{~m}^{3} / \mathrm{h}$ \\
Maksimum Sapma & $\% 0,2$ \\
Şebeke (test odası modülü) & $230 \mathrm{~V} / 50 \mathrm{~Hz} / 16 \mathrm{~A}$ \\
Menşei & Almanya \\
\hline
\end{tabular}

\section{B. GÜRÜLTÜ ÖLÇÜMÜ}

Davlumbazların gürültü seviyesini ölçmek için test prosedürü IEC 60704 numaralı uluslararası standardın'da belirtilmiştir. Yapılan bu çalışmada gürültü ölçüm testleri, uluslararası standart olan IEC 60704 ile uyumlu ve yarı çınlamalı gürültü odasında ölçülmüştür [18]. Deneysel testlere ait ürün, test düzeneği ve test düzeneğinin şematik hali Şekil 5'te gösterilmiştir.

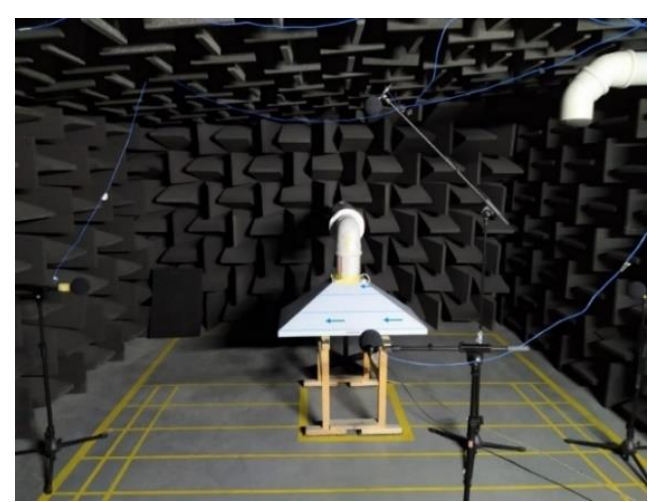

Şekil 5. Gürültü performans testi ve gürültü odası mikrofon yerleşimi. 


\section{YAĞ FILLTRESİ VERIMLILIIK ÖLÇÜMÜ}

Yağ filtreleri yemek pişirme esnasında çıkan yağın, alevin ve dumanın yayılmasını önler [10]. Yăg filtresi verimliliğinin ölçümü, uluslararası standart olan IEC 61591 ile uyumlu şekilde yağ filtreleme verimliliği endeksi olarak Eşitlik 3'te gösterildiği gibi hesaplanmaktadır. Hesaplamalardaki tüm ağıllıklar gram olarak değerlendirilir [17]. Tartma işlemleri IEC 61591 standart'ında belirtildiği gibi kuru koşullarda yapılır, bu işlem tartma esnasındaki kalan nemin etkisini önlemektedir. Deneylerde 2 tip filtre kullanılmıştır. Bu filtreler 3 katmanlı ve 5 katmanlı alüminyum filtrelerdir. Test düzeneği ve deney düzeneğinin şematik hali Şekil 6'da gösterilmiştir.

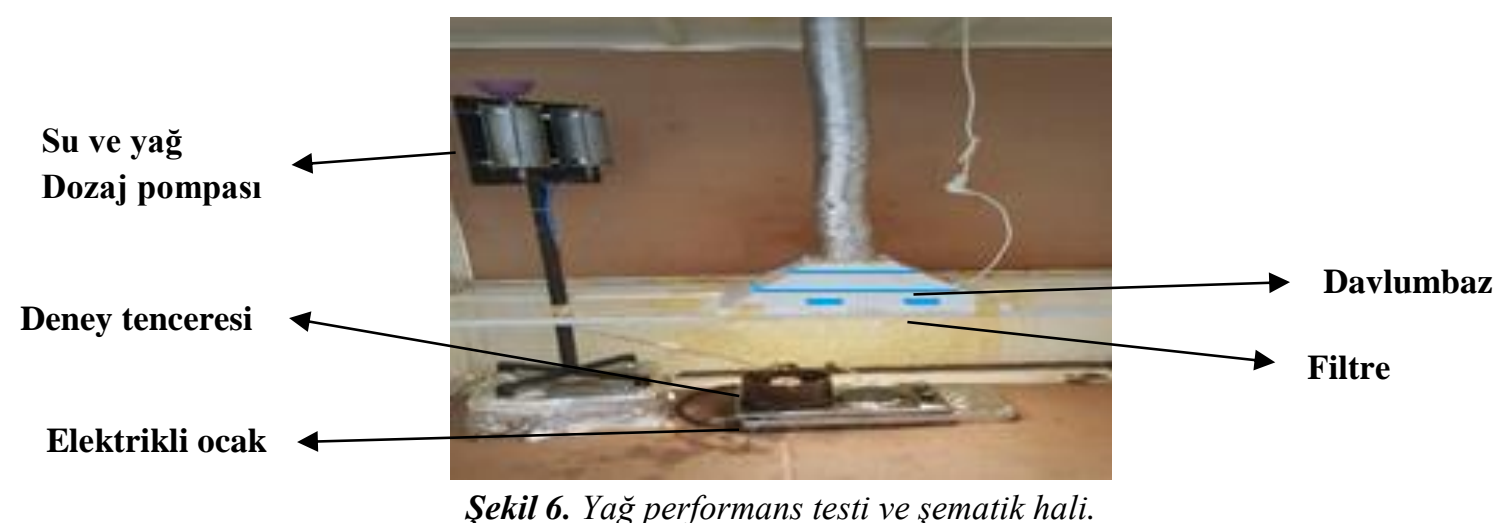

\section{DENEYSEL ve İSTATIKSEL SONUCLARI}

\section{A. DENEY SONUÇLARI}

Taguchi yöntemi, geleneksel deney tasarımının dikkate almadığı kontrol edilemeyen faktörlerin meydana getirdiği değişkenlerin denetimine izin vermekte olup deney sayısının önemli derecede azaltılması ve ideal kesme şartlarının belirlenmesi için basit, verimli ve sistematik bir çözüm sunmaktadır [21-24]. Deney parametre ve seviyeleri Taguchi $\mathrm{L}_{8}$ ortogonal deney tasarımı yöntemi kullanılarak oluşturulmuş ve Tablo 2 'de gösterilen $2^{3}(8)$ adet deney farklı özelliğe sahip davlumbazlar üretilmiştir. Deneylerde bu ürünlere ait performans, gürültü seviye ve yağ verimlilik değerleri hesaplanmıştır. Yapılan deneyler sonucu oluşan en verimli noktadaki debi $\left(\mathrm{m}^{3} / \mathrm{h}\right)$, yıllık enerji tüketimi $(\mathrm{kWh})$, maksimum devirde debi $\left(\mathrm{m}^{3} / \mathrm{h}\right)$, gürültü seviyesi $(\mathrm{dB})$, yağ verimlilik endeksi $\left(\mathrm{G}_{\mathrm{FE}} \%\right)$ değerleri Tablo 4'te gösterilmiştir. 
Tablo 4. Deney parametreleri ve sonuçlart.

\begin{tabular}{|c|c|c|c|c|c|c|c|c|}
\hline \multicolumn{4}{|c|}{ Girdi Parametreleri } & \multicolumn{5}{|c|}{ Çıktı Parametreleri } \\
\hline Deney No & $\mathbf{A}$ & B & $\mathbf{C}$ & $\begin{array}{c}\mathbf{Q}_{\mathrm{BEP}} \\
\left(\mathbf{m}^{3} / \mathbf{h}\right)\end{array}$ & $\begin{array}{c}\text { AEC } \\
(\mathbf{k W h})\end{array}$ & $\begin{array}{c}\text { Max. } \\
\text { devirde } \\
\text { hava akışı } \\
\left(\mathbf{m}^{3} / \mathbf{h}\right) \\
\end{array}$ & $\begin{array}{l}\mathbf{L}_{\mathrm{WA}} \\
(\mathrm{dB})\end{array}$ & $\begin{array}{c}\text { Yağ } \\
\text { Filt. } \\
\text { Verimi } \\
\left(\mathbf{G}_{\mathrm{FE}} \%\right) \\
\end{array}$ \\
\hline 1 & 60 & 3 & 450 & 255,8 & 62,6 & 487,1 & 65 & 75,9 \\
\hline 2 & 60 & 3 & 650 & 355,2 & 43,6 & 657,9 & 65 & 80,3 \\
\hline 3 & 60 & 5 & 450 & 245,7 & 62,7 & 486 & 64 & 76,1 \\
\hline 4 & 60 & 5 & 650 & 369,1 & 44,5 & 651,7 & 65 & 80,6 \\
\hline 5 & 90 & 3 & 450 & 261,2 & 62,9 & 508,5 & 52,9 & 74,3 \\
\hline 6 & 90 & 3 & 650 & 350,1 & 48,7 & 666,4 & 66,6 & 68,4 \\
\hline 7 & 90 & 5 & 450 & 260,6 & 63 & 508,3 & 53,2 & 74,5 \\
\hline 8 & 90 & 5 & 650 & 383,4 & 51,1 & 663,1 & 66 & 68,7 \\
\hline
\end{tabular}

Farklı komponentler ile toplanan davlumbazların en verimli noktadaki debi $\left(\mathrm{m}^{3} / \mathrm{h}\right)$, ylllık enerji tüketimi $(\mathrm{kWh})$, maksimum devirde debi $\left(\mathrm{m}^{3} / \mathrm{h}\right)$, gürültü seviyesi $(\mathrm{dB})$ ve yağ verimlilik endeksi $\left(\mathrm{G}_{\mathrm{FE}} \%\right)$ değerleri incelendiğinde en verimli noktadaki en düşük debi değeri $245,7 \mathrm{~m}^{3} / \mathrm{h}$ olarak 3 nolu deneyde ve en yüksek debi $383,4 \mathrm{~m}^{3} / \mathrm{h}$ olarak 8 nolu deneyde ölçülmüştür. Y1llık enerji tüketimi incelendiğinde en düşük enerji tüketiminin 2 nolu deneyde 43,6 kWh olarak, en yüksek enerji tüketiminin ise 7 nolu deneyde $63,0 \mathrm{kWh}$ olarak ölçülmüştür. Burada en düşük enerji tüketimi ile en büyük enerji tüketimi arasında yaklaşı \% 44,5 fark olduğu görülmektedir. Davlumbazların maksimum devirde hava akış1 en küçük 486,0 ( $\left.\mathrm{m}^{3} / \mathrm{h}\right)$ olarak, en büyük ise 6 nolu deneyde $666,4\left(\mathrm{~m}^{3} / \mathrm{h}\right)$ olarak ölçülmüştür. Burada en düşük hava debisi ile en büyük hava debisi arasında yaklaşı \%37 fark olduğu görülmektedir.

Gürültü seviyeleri üzerinde davlumbaz motorlarınınının hava akış miktarlarında etkili olduğu görülmektedir. Maksimum devirde yapılan gürültü performans sonuçları incelendiğinde en küçük 53 $\mathrm{dB}$ olarak 5 ve 7 nolu deneyde, en büyük $67 \mathrm{~dB}$ olarak 6 nolu deneyde ölçülmüsşür. En düşük gürültü seviyesi ile en büyük gürültü seviyesi arasında yaklaşık \%26,4 fark olduğu görülmektedir. Yağ filtresi verimliliği incelendiğinde genel olarak $60 \mathrm{~cm}$ ebatlara sahip ürünlerde yağ filtresi performansı daha yüksek çıktığı belirlenmiştir. $60 \mathrm{~cm}$ ürünlerin $90 \mathrm{~cm}$ ürünlere göre performansının daha yüksek çıkması ürünün tuttuğu yağın kütlesinin $\left(\mathrm{w}_{\mathrm{r}}(\mathrm{g})\right)$ daha az olmasından kaynaklanmaktadır. Yağ filtresi verimliliği en düşük \%68,4 olarak 6 nolu deneyde ve en yüksek \%80,6 olarak 4 nolu deneyde ölçülmüşsür. En düşük $\mathrm{Q}_{\text {BEP }}$ değerinin 3 nolu (Şekil 7) deneyde $245,7 \mathrm{~m}^{3} / \mathrm{h}$, , maksimum hava akışının ise $486 \mathrm{~m}^{3} / \mathrm{h}$ olarak ölçüldüğü görülmüştür. Deney 8 ile elde edilen sonuçların grafikleri (Şekil 8) incelendiğinde $Q_{\text {вEP }}$ değerinin $383,4 \mathrm{~m}^{3} / \mathrm{h}$ olarak, maksimum devirde hava akışının ise $663,1 \mathrm{~m}^{3} / \mathrm{h}$ olarak ölçüldüğü tespit edilmiştir. 


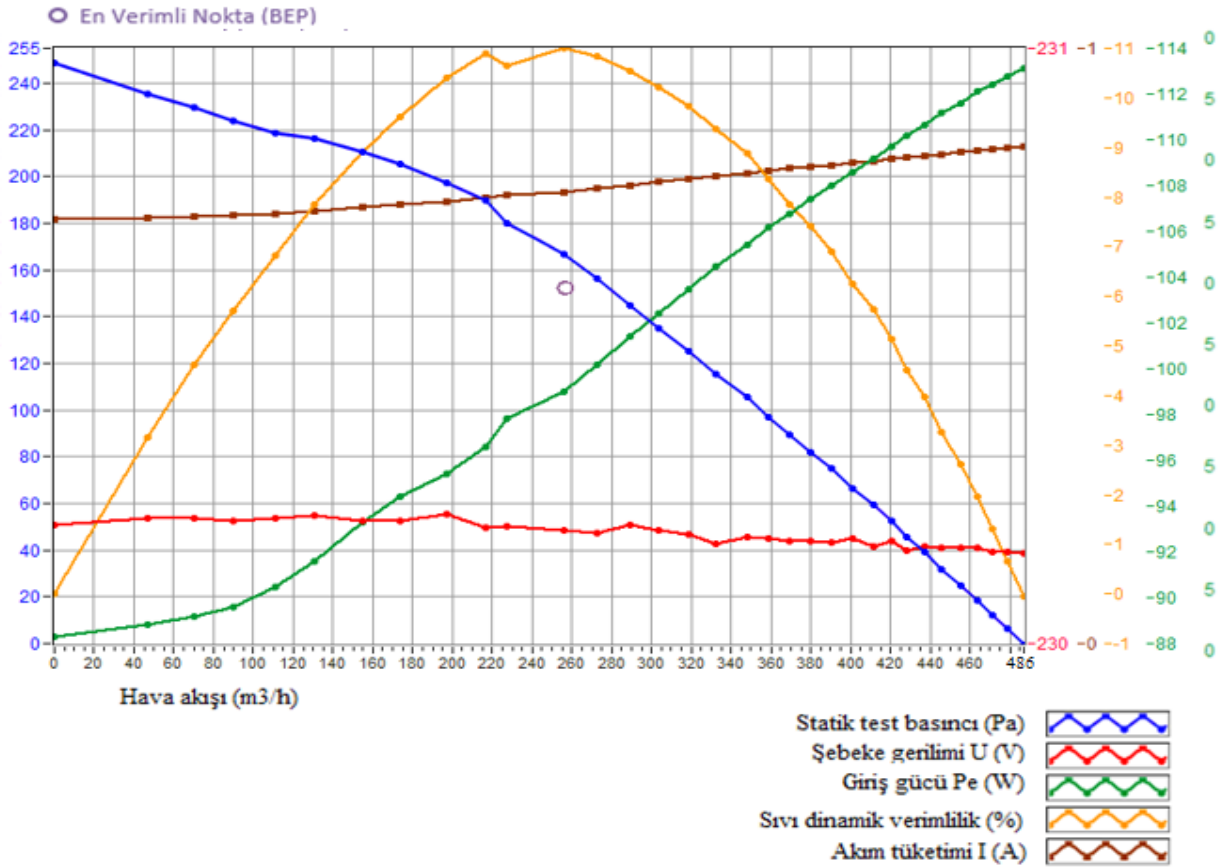

Şekil 7. 3 nolu deneye ait performans grafiği.

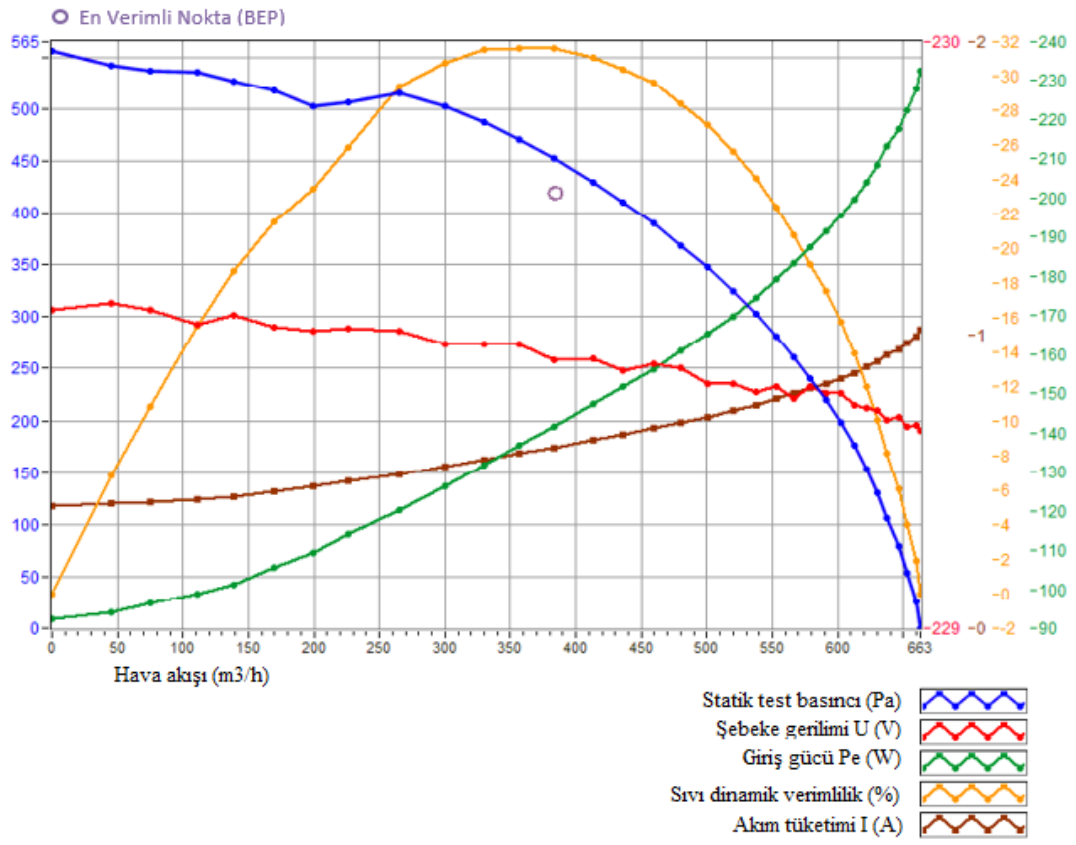

Şekil 8. 8 nolu deneye ait performans grafiği.

\section{B. SINYAL-GÜRÜLTÜ ANALIZİ (S/N)}

$\mathrm{S} / \mathrm{N}$ oranı, Taguchi metodunun performans karakteristiklerini istatiksel olarak ölçen bir araç olup, amaç fonksiyonu olarak tanımlanan cevabın logaritmik bir fonksiyonudur [25-26]. Yapılan bu çalışmada en verimli noktadaki hava debisi $\left(\mathrm{Q}_{\mathrm{BEP}}\right)$, maksimum hava akışı ve yağ filtresi verimliliği oranlarının büyük olması ürünün performansını arttıracağından dolayı kalite karakteristiği olarak “(S/N), en büyük-en iyisi” seçilmiştir. Y1llık enerji tüketimi ve gürültü seviyesi $\left(\mathrm{L}_{\mathrm{WA}}\right)$ oranlarının küçük olması ile ürün enerji ve performans avantajı sağlayacağından kalite karakteristiği (ayırıcı 
nitelik) olarak “(S/N), en küçük-en iyisi” seçilmiştir. [27]. Deney sonucunda elde edilen değerlerin her birinin $\mathrm{S} / \mathrm{N}$ oranları, en verimli noktadaki debi $\left(\mathrm{m}^{3} / \mathrm{h}\right)$, yıllık enerji tüketimi $(\mathrm{kWh})$, maksimum devirde debi $\left(\mathrm{m}^{3} / \mathrm{h}\right)$, gürültü seviyesi $(\mathrm{dB})$ ve yağ verimlilik endeksi $\left(\mathrm{G}_{\mathrm{FE}} \%\right)$ değerleri Taguchi yöntemi ile hesaplanarak Tablo 5'te gösterilmiştir.

Tablo 5. Deney parametreleri ile toplanan davlumbazların sinyal gürültü oranlart.

\begin{tabular}{|c|c|c|c|c|c|c|c|c|c|c|c|}
\hline \multicolumn{12}{|c|}{ Sinyal/Gürültü Oranları } \\
\hline \multicolumn{4}{|c|}{$\mathbf{Q}_{\text {BEP }}\left(\mathbf{m}^{3} / \mathbf{h}\right)$} & \multicolumn{4}{|c|}{ AEC(kWh) } & \multicolumn{4}{|c|}{ Maksimum hava akışı $\left(\mathrm{m}^{3} / \mathbf{h}\right)$} \\
\hline Level & Boyut & Filtre & Motor & Level & Boyut & Filtre & Motor & Level & Boyut & Filtre & Motor \\
\hline 1 & 49,58 & 49,60 & 48,16 & 1 & $-34,41$ & $-34,61$ & $-35,96$ & 1 & 55,03 & 55,18 & 53,93 \\
\hline 2 & 49,80 & 49,79 & 51,23 & 2 & $-34,97$ & $-34,77$ & $-33,42$ & 2 & 55,29 & 55,14 & 56,39 \\
\hline Delta & 0,22 & 0,19 & 3,07 & Delta & 0,56 & 0,16 & 2,54 & Delta & 0,26 & 0,04 & 2,45 \\
\hline Rank & 2 & 3 & 1 & Rank & 2 & 3 & 1 & Rank & 2 & 3 & 1 \\
\hline \multicolumn{6}{|c|}{$\mathrm{L}_{\mathrm{WA}}(\mathrm{dB})$} & \multicolumn{6}{|c|}{ Yağ Filtresi Verimliliği $\left(\mathrm{G}_{\mathrm{FE}} \%\right)$} \\
\hline & Level & Boyut & Filtre & Motor & & & Level & Boyut & Filtre & Motor & \\
\hline & 1 & $-36,22$ & $-35,86$ & $-35,34$ & & & 1 & 37,86 & 37,46 & 37,52 & \\
\hline & 2 & $-35,46$ & $-35,82$ & $-36,34$ & & & 2 & 37,08 & 37,48 & 37,42 & \\
\hline & Delta & 0,76 & 0,04 & 1,00 & & & Delta & 0,79 & 0,03 & 0,11 & \\
\hline & Rank & 2 & 3 & 1 & & & Rank & 1 & 3 & 2 & \\
\hline
\end{tabular}

Tablo 5 incelendiğinde en verimli noktadaki debi için en ideal parametreler, boyut, filtre ve motor için Seviye 2, yıllık enerji tüketimi için en ideal parametreler, boyut ve filtre için Seviye 1, motor için Seviye 2 olarak, maksimum devirde hava akışı için en ideal parametreler, boyut, filtre ve motor için Seviye 2, gürültü performansı için en ideal parametreler, boyut ve filtre için Seviye 2, motor için Seviye 1, yağ filtresi verimliliği için en ideal parametreler, boyut ve motor için Seviye 1, filtre için Seviye 2 olarak belirlenmiş ve grafik olarak ise Şekil 9'da gösterilmiştir.

a) $Q_{B E P}\left(m^{3} / h\right)$

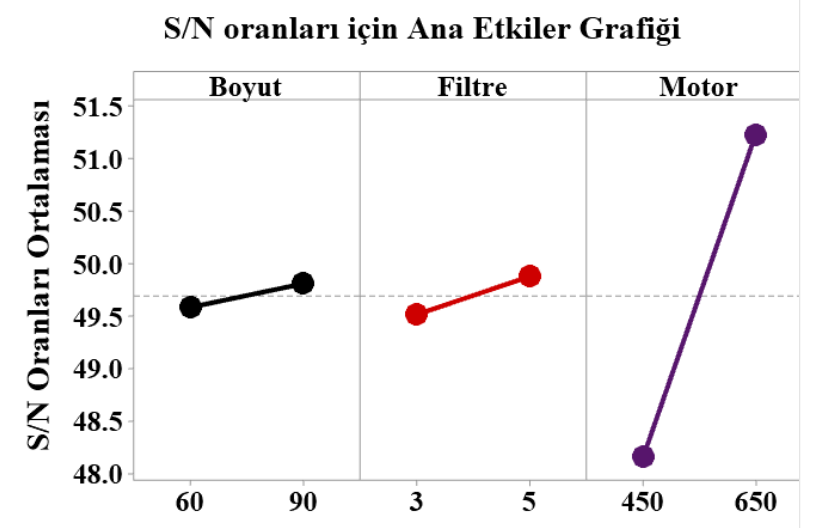

Sinyal Gürültü Orant: En büyük en iyi b) $A E C(k W h)$

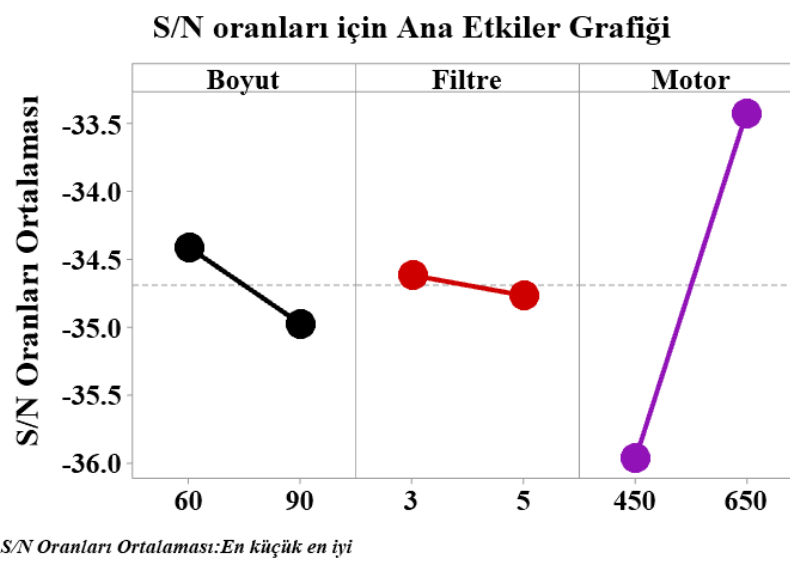

d) $L_{W A}(d B)$ 

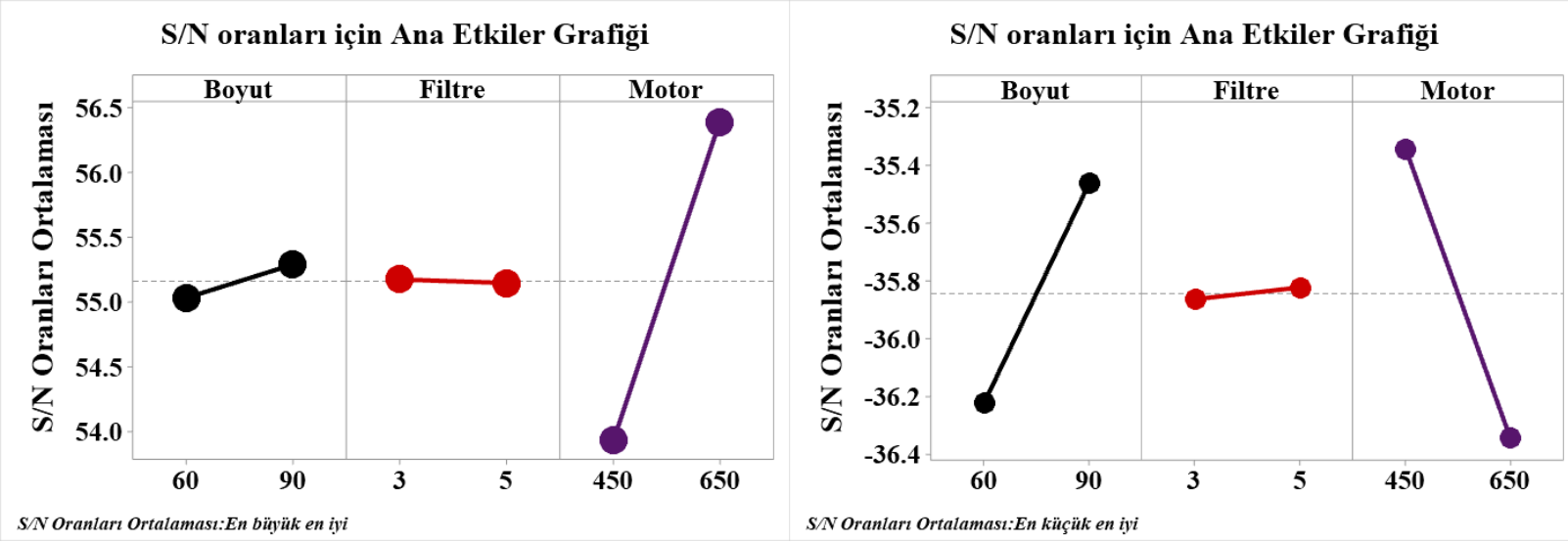

e) Yă̆ Filtresi Verimliliğ $\left(G_{F E} \%\right)$

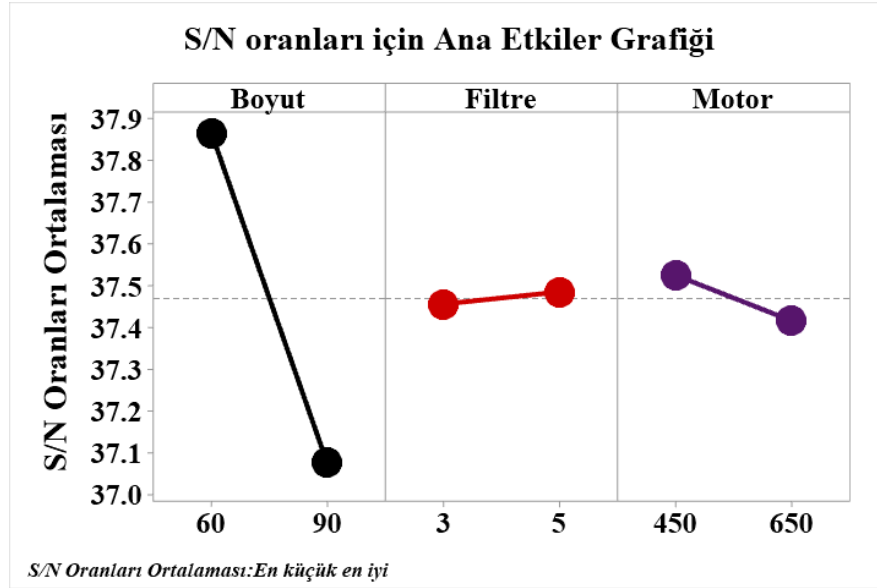

Şekil 9. Sinyal gürültü oranlart için ana etkiler grafiği. a) $\left.\left.Q_{B E P}, \boldsymbol{b}\right) A E C, \boldsymbol{c}\right)$ Maksimum devirde hava aklşl, d) Gürültü performansı ve e) Yağ filtresi verimliliği grafiğini göstermektedir.

\section{ANOVA}

ANOVA, kontrol faktörlerinin birbirleri arasındaki etkileşimlerin belirlenmesinde istatiksel olarak kullanılan bir yöntemdir [28]. Bu çalışmada gerçekleştirilen analiz $\% 95$ güven ve $\% 5$ anlamlılık seviyesinde gerçekleştirilmiştir [29]. Tablo 6' da davlumbazlarda kullanılan komponentlerinin en verimli noktadaki debi $\left(\mathrm{m}^{3} / \mathrm{h}\right)$, yıllık enerji tüketimi $(\mathrm{kWh})$, maksimum devirde debi $\left(\mathrm{m}^{3} / \mathrm{h}\right)$, gürültü seviyesi $(\mathrm{dB})$ ve yağ verimlilik endeksi $\left(\mathrm{G}_{\mathrm{FE}} \%\right)$ üzerindeki sayısal etkilerini göstermektedir. Yapılan deneyler sonucu $\mathrm{Q}_{\mathrm{BEP}}$, yıllık enerji tüketim, maksimum devirde hava akışı üzerindeki en etkili işlem parametresinin sırası ile \%96,62, \%93,02 ve \%98,87 olarak davlumbaz motoru olduğu belirlenmiştir. Gürültü performansı üzerindeki en etkili işlem parametresinin \%41,45 ile davlumbaz motoru ve etkili ikinci parametrenin ise \%22,59 ile ürün boyutu olduğu görülmüştür. Yağ filtre performansı üzerindeki en etkili işlem parametresinin \%62,72 ile ürün boyutu olduğu tespit edilmiştir. Anavo sonuçlarına göre davlumbazların üretiminde kullanılan bileşenlerin ürün verimi üzerinde etkisinin düşük olduğu parametreler incelendiğinde, $\mathrm{Q}_{\text {веP }}$ için ürün boyutu, $\mathrm{AEC}$, maksimum devirde hava akışı, gürültü performansı ve yağ filtresi verimliliği için ise filtre olduğu belirlenmiştir. Yapılan çalışma ile davlumbaz bileşenlerinden filtrenin, ürünün verimliliği üzerine etkisinin düşük olduğu tespit edilmiştir. 
Tablo 6. Anova varyans analizi a) $Q_{B E P}$, b) AEC, c) Maksimum devirde hava akışl, d) Gürültü performansı ve e) Yă̆ filtresi verimliliği tablosunu göstermektedir.

\begin{tabular}{|c|c|c|c|c|c|c|c|}
\hline \multicolumn{8}{|c|}{ a) $Q_{B E P}\left(m^{3} / h\right)$} \\
\hline Kaynak & DF & Seq SS & Katk1 & Adj SS & Adj MS & F-Değer & P-Değer \\
\hline Boyut & 1 & 108,8 & $0,45 \%$ & 108,8 & 108,8 & 0,79 & 0,424 \\
\hline Filtre & 1 & 166,5 & $0,68 \%$ & 166,5 & 166,5 & 1,21 & 0,333 \\
\hline Motor & 1 & 23598,8 & $96,62 \%$ & 23598,8 & 23598,8 & 171,28 & 0,000 \\
\hline Hata & 4 & 551,1 & $2,26 \%$ & 551,1 & 137,8 & & \\
\hline Total & 7 & 24425,2 & $100,00 \%$ & & & & \\
\hline \multicolumn{8}{|c|}{ R-sq: $97,74 \%$} \\
\hline \multicolumn{8}{|c|}{ b) $\mathrm{AEC}(\mathbf{k W h})$} \\
\hline Kaynak & DF & Seq SS & Katk1 & Adj SS & Adj MS & F-Değer & P-Değer \\
\hline Boyut & 1 & 18,911 & $3,51 \%$ & 18,911 & 18,911 & 4,41 & 0,104 \\
\hline Filtre & 1 & 1,531 & $0,28 \%$ & 1,531 & 1,531 & 0,36 & 0,582 \\
\hline Motor & 1 & 500,861 & $93,02 \%$ & 500,861 & 500,861 & 116,72 & 0,000 \\
\hline Hata & 4 & 17,165 & $3,19 \%$ & 17,165 & 4,291 & & \\
\hline Total & 7 & 538,469 & $100,00 \%$ & & & & \\
\hline \multicolumn{8}{|c|}{ R-sq: $96,81 \%$} \\
\hline \multicolumn{8}{|c|}{ c) Maximum devirde hava akışı $\left(\mathrm{m}^{3} / \mathrm{h}\right)$} \\
\hline Kaynak & DF & Seq SS & Katk1 & Adj SS & Adj MS & F-Değer & P-Değer \\
\hline Boyut & 1 & 505,6 & $0,95 \%$ & 505,6 & 505,6 & 24,81 & 0,008 \\
\hline Filtre & 1 & 14,6 & $0,03 \%$ & 14,6 & 14,6 & 0,72 & 0,445 \\
\hline Motor & 1 & 52682,6 & $98,87 \%$ & 52682,6 & 52682,6 & 2585,17 & 0,000 \\
\hline Hata & 4 & 81,5 & $0,15 \%$ & 81,5 & 20,4 & & \\
\hline Total & 7 & 53284,3 & $100,00 \%$ & & & & \\
\hline \multicolumn{8}{|c|}{ R-sq: $99,85 \%$} \\
\hline \multicolumn{8}{|c|}{ d) $\mathrm{L}_{\mathrm{WA}}(\mathrm{dB})$} \\
\hline Kaynak & DF & Seq SS & Katk1 & Adj SS & Adj MS & F-Değer & P-Değer \\
\hline Boyut & 1 & 51,511 & $22,59 \%$ & 51,5113 & 51,5113 & 2,52 & 0,188 \\
\hline Filtre & 1 & 0,211 & $0,09 \%$ & 0,2112 & 0,2112 & 0,01 & 0,924 \\
\hline Motor & 1 & 94,531 & $41,45 \%$ & 94,5312 & 94,5312 & 4,62 & 0,098 \\
\hline Hata & 4 & 81,795 & $35,87 \%$ & 81,7950 & 20,4487 & & \\
\hline Total & 7 & 228,049 & $100,00 \%$ & & & & \\
\hline \multicolumn{8}{|c|}{ R-sq: $64,13 \%$} \\
\hline \multicolumn{8}{|c|}{ e) Yağ Filtresi Verimliliği $\left(\mathrm{G}_{\mathrm{FE}} \%\right)$} \\
\hline Kaynak & $\mathrm{DF}$ & Seq SS & Katk1 & Adj SS & Adj MS & F-Değer & P-Değer \\
\hline Boyut & 1 & 91,125 & $62,72 \%$ & 91,1250 & 91,1250 & 6,87 & 0,059 \\
\hline Filtre & 1 & 0,125 & $0,09 \%$ & 0,1250 & 0,1250 & 0,01 & 0,927 \\
\hline Motor & 1 & 0,980 & $0,67 \%$ & 0,9800 & 0,9800 & 0,07 & 0,799 \\
\hline Hata & 4 & 53,050 & $36,52 \%$ & 53,0500 & 13,2625 & & \\
\hline Total & 7 & 145,280 & $100,00 \%$ & & & & \\
\hline & & & sq: $63,48 \%$ & & & & \\
\hline
\end{tabular}




\section{REGRESYON ANALİZI VE TAHMINI SONUÇLAR}

Regresyon analizleri, bir bağımlı değişken ile bir veya daha fazla bağımsız değişken arasındaki ilişkiye sahip çeşitli değişkenlerin modellenmesi ve analizi için gerçekleştirilir [28]. Bu çalışmada sekiz farklı kombinasyon ile oluşturulmuş davlumbazlarda kullanılan komponentlerin en verimli noktadaki debi $\left(\mathrm{m}^{3} / \mathrm{h}\right)$, yıllık enerji tüketimi $(\mathrm{kWh})$, maksimum devirde debi $\left(\mathrm{m}^{3} / \mathrm{h}\right)$, gürültü seviyesi (dB) ve yağ verimlilik endeksi $\left(\mathrm{G}_{\mathrm{FE}} \%\right)$ regresyon analizi ile oluşturulan denklemler Tablo 7 ' de gösterilmektedir.

Tablo 7. Deneyler sonuçları için tahmini eşitlikleri.

\begin{tabular}{lll}
\hline \multicolumn{1}{c}{$\operatorname{QBEP}\left(\mathrm{m}^{3} / \mathrm{h}\right)$} & $=$ & $-25,3+0,246$ Boyut $+4,56$ Filtre $+0,5431$ Motor \\
$\mathrm{AEC}(\mathrm{kWh})$ & $=88,97+0,1025$ Boyut $+0,438$ Filtre $-0,07913$ Motor \\
$\mathrm{L}_{\mathrm{WA}}(\mathrm{dB})$ & $=56,6-0,169$ Boyut- 0,16 Filtre $+0,0344$ Motor \\
Maximum hızda hava akışı $\left(\mathrm{m}^{3} / \mathrm{h}\right)$ & $=97,9+0,530$ Boyut $-1,35$ Filtre $+0,8115$ Motor \\
Yağ Filtresi Verimliliği $(\mathrm{GFE} \%)$ & $=93,1-0,2250$ Boyut $+0,12$ Filtre $-0,0035$ Motor \\
\hline
\end{tabular}

Deneysel sonuçlardan elde edilen değerlerin CI (güven aralığı) dahilinde olup olmadığını belirlemek için ikinci dereceden regresyon analizi uygulanmıştır. Bu analiz, deney sonuçları ile tahmini (PI) deney sonuçları arasındaki ilişkiyi belirlemek için Taguchi optimizasyon metodu kullanılarak yapılmıştır. Sonuçlar değerlendirildiğinde, regresyon analizinde tahmini değerlerin CI sınırında (\% 95) olduğu tespit (Şekil 10) edilmiştir. Tablo 8'de deneylerin tahmini sonuçları gösterilmektedir.

Tablo 8. Deneylerin tahmini sonuçlart.

\begin{tabular}{|c|c|c|c|c|c|c|c|c|}
\hline \multicolumn{4}{|c|}{ Girdi Parametreleri } & \multicolumn{5}{|c|}{ Çıktı Parametreleri } \\
\hline $\begin{array}{c}\text { Deney } \\
\text { No }\end{array}$ & $\mathbf{A}$ & B & $\mathbf{C}$ & $\begin{array}{c}\text { Tahmin } \\
\text { QBEP } \\
\left(\mathbf{m}^{3} / \mathbf{h}\right)\end{array}$ & $\begin{array}{c}\text { Tahmin } \\
\text { AEC } \\
(\mathbf{k W h})\end{array}$ & $\begin{array}{c}\text { Tahmin } \\
\text { Max. } \\
\text { devirde } \\
\text { hava akış } \\
\left(\mathrm{m}^{3} / \mathbf{h}\right)\end{array}$ & $\begin{array}{l}\text { Tahmin } \\
\text { Gürültü } \\
\text { (dB) }\end{array}$ & $\begin{array}{c}\text { Tahmin } \\
\text { Yağ } \\
\text { Filtresi } \\
\left(\mathbf{G}_{\mathrm{FE}} \%\right)\end{array}$ \\
\hline 1 & 60 & 3 & 450 & 252,04 & 62,43 & 487,1 & 64,76 & 75,9 \\
\hline 2 & 60 & 3 & 650 & 351,43 & 43,43 & 657,9 & 65,23 & 80,3 \\
\hline 3 & 60 & 5 & 450 & 249,46 & 62,86 & 486,0 & 64,23 & 76,1 \\
\hline 4 & 60 & 5 & 650 & 372,86 & 44,66 & 651,7 & 64,70 & 80,6 \\
\hline 5 & 90 & 3 & 450 & 257,43 & 62,73 & 508,5 & 53,13 & 74,3 \\
\hline 6 & 90 & 3 & 650 & 353,86 & 48,86 & 666,4 & 66,36 & 68,4 \\
\hline 7 & 90 & 5 & 450 & 264,36 & 63,16 & 508,3 & 52,96 & 74,5 \\
\hline 8 & 90 & 5 & 650 & 379,63 & 50,93 & 663,1 & 66,23 & 68,7 \\
\hline
\end{tabular}



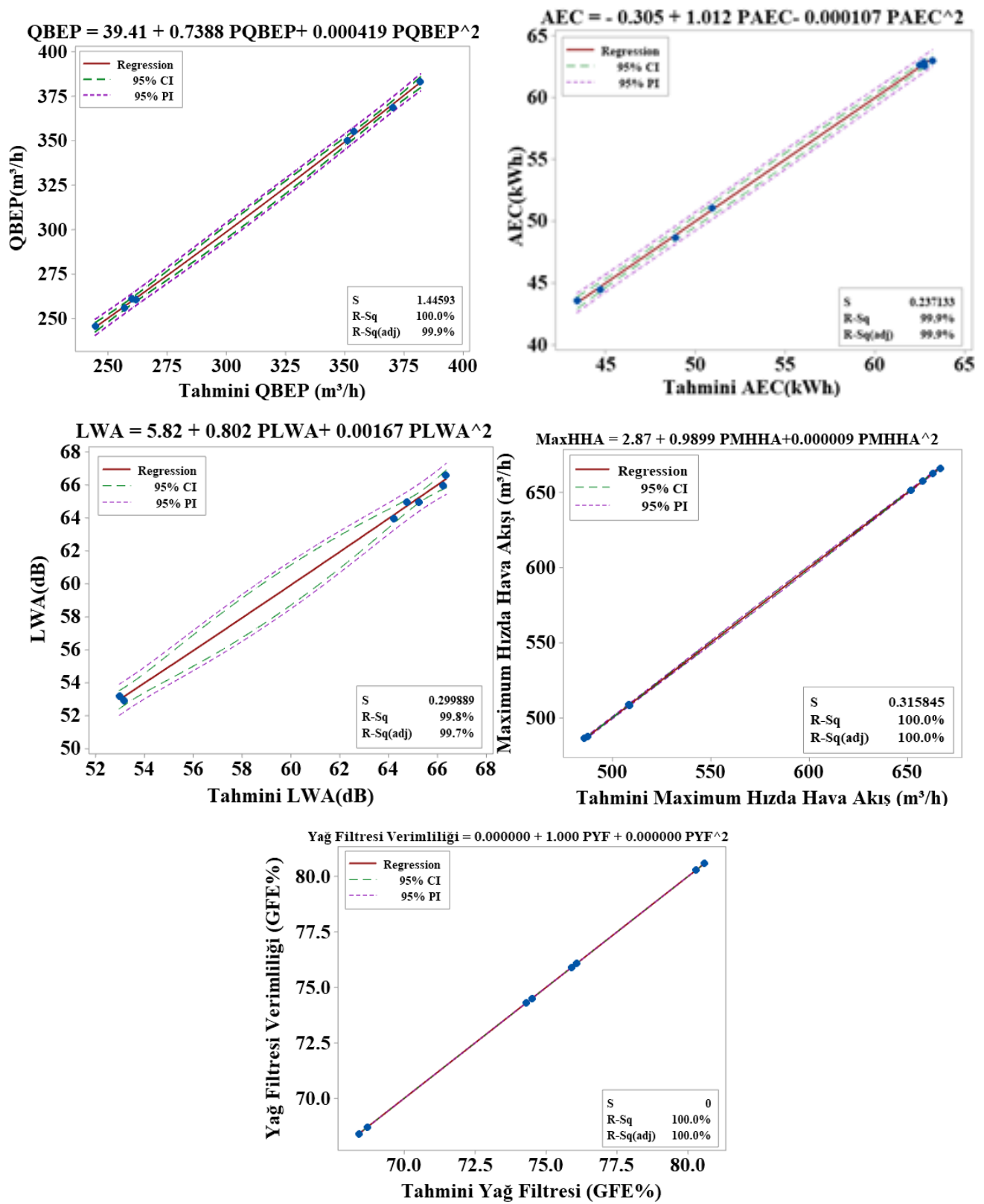

Şekil 10. Deney sonuçları ile tahmini deney sonuçları arasındaki ilişsi grafikleri

\section{V.SONUCLAR}

Yapılan bu çalışmada, mutfaklarda kullanılan davlumbazların performansına etki eden komponentlerin deneysel ve istatiksel olarak incelenmiştir. Yapılan çalışmadan elde edilen sonuçlar maddeler halinde verilmiştir.

- Farklı komponentler ile üretimi gerçekleştirilen davlumbazların en verimli noktadaki debi değerinin en küçük $245,7 \mathrm{~m}^{3} / \mathrm{h}$ ve en büyük $383,4 \mathrm{~m}^{3} / \mathrm{h}$ olduğu,

- Deneyde kullanılan davlumbazların yıllık enerji tüketimi incelendiğinde en küçük enerji tüketimi 43,6 kWh ve en büyük enerji tüketimi $63,0 \mathrm{kWh}$ olduğu, 
- Davlumbazların, maksimum devirde hava akışı en küçük $486,0 \mathrm{~m}^{3} / \mathrm{h}$ ve en büyük $666,4 \mathrm{~m}^{3} / \mathrm{h}$ olduğu,

- Maksimum devirde yapılan gürültü performans sonuçları incelendiğinde en küçük gürültü performansının $53 \mathrm{~dB}$, en büyük gürültü performansının $67 \mathrm{~dB}$ olduğu,

- Deneyden elde edilen verilere göre; iyi bir komponent seçimi ile oluşturulmuş davlumbazın yıllık enerji tüketimde $\% 31$ azalma, gürültü performansında $\% 21$ iyileşme ve en verimli noktadaki debinin \%17,1 arttığı görülmektedir.

- Yağ filtresi verimliliğinin en küçük 6 nolu deneyde $\% 68,4$ ve en büyük 4 nolu deneyde $\% 80,6$ olduğu,

- Sinyal gürültü oranlarına göre $\mathrm{Q}_{\text {BEP }}$ ve maksimum devirde hava akışı için en ideal parametreler, boyut, filtre ve motor için Seviye 2, AEC için en ideal parametreler, boyut ve filtre için Seviye 1, motor için Seviye 2, $\mathrm{L}_{\mathrm{WA}}$ için en ideal parametreler, boyut ve filtre için Seviye 2, motor için Seviye 1, yağ filtresi verimliliği için en ideal parametreler, boyut ve motor için Seviye 1, filtre için Seviye 2 olarak belirlendiği,

- Anova sonuçları incelendiğinde $\mathrm{Q}_{\mathrm{BEP}}, \mathrm{AEC}$, Maksimum devirde hava akışı ve $\mathrm{L}_{\mathrm{WA}}$ için en etkili komponentin suras1 ile $\% 96,62, \% 93,02, \% 98,87, \% 41,45$ oranla motor olduğu, yă filtresi verimliliği için en etkili parametrenin \%62,72 oranla boyut olduğu,

- Yapılan çalışmaya ek olarak ilerleyen süreçte davlumbazda kullanılan filtre ve davlumbaz tasarımının yağ tutma verimliliği üzerine hesaplamalı akışkanlar dinamiği yöntemi ile optimizasyon çalışması yapılabileceği düşünülmektedir.

TEȘEKKÜR: $\mathrm{Bu}$ çalışmada hiçbir yardımı esirgemeyen Silverline Endüsrtri A.Ş.'ye ve çalışanlarına, ayrıca desteklerinden dolayı Ar-GE direktörü Semra ARSLAN'a teşekkür ederiz.

\section{KAYNAKLAR}

[1] M. Liddament, "A Guide to Energy Efficient Ventilation, Air Infiltration and Ventilation Centre," Sint-Stevens-Woluwe. Belgium, 85, 9, 1996.

[2] P. Concannon, "Technical Note AIVC 57: Residential Ventilation," Brussels, Air Infiltration and Ventilation Center, 2002.

[3] P. G. Schild, "State-of-the-art of low-energy residential ventilation," Contributed Report 7 (2007).

[4] B. Lundbäck, "Epidemiology of rhinitis and asthma," Clinical and experimental allergy: journal of the British Society for Allergy and Clinical Immunology, vol. 28, pp. 3-10, 1998. 
[5] J. Heinrich, "Influence of indoor factors in dwellings on the development of childhood asthma," International journal of hygiene and environmental health, vol. 214.1, pp. 1-25, 2011.

[6] P. Jacobs, E. Cornelissen, and W. Borsboom, "Energy efficient measures to reduce PM2, 5 emissions due to cooking," Indoor Air conference, TNO, Delft, Netherlands, 2016.

[7] P. Cicconi, D. Landi, M. Germani and A.C. Russo, "A support approach for the conceptual design of energy-efficient cooker hoods," Applied Energy, vol. 206, pp. 222-239, 2017.

[8] K. Gillingham, R.G. Newell and K. Palmer, "Energy efficiency economics and policy," Annual Review of Resource Economics, vol. 1, pp. 597-620, 2009.

[9] Z. Wang, X. Wang, and D. Guo, "Policy implications of the purchasing intentions towards energyefficient appliances among China's urban residents: Do subsidies work?," Energy Policy, vol. 102, pp. 430-439, 2017.

[10] P. Cicconi, M. Germani, D. Landi and A.C. Russo "A design methodology to predict the product energy efficiency through a configuration tool," Advances on Mechanics, Design Engineering and Manufacturing, Springer, Cham, pp. 1095-1105, 2017.

[11] N. Fujimura, H. Kotani, T. Yamanaka, Y. Momoi, K. Sagara \& K. Masui, "C\&C efficiency of canopy hood exposed to horizontal air stream in commercial kitchen calculated by CFD analysis," International Journal of Ventilation, vol. 16, no. 3, pp. 213-229, 2017.

[12] H. Kotani, T. Yamanaka, K. Sagara \& S. Chihara, "High efficiency exhaust hood with baffle plate for commercial kitchen," In 9th International Conference on Industrial Ventilation, Japan, 2009.

[13] Y. Zhao, A. Li, P. Tao \& R. Gao, "The impact of various hood shapes, and side panel and exhaust duct arrangements, on the performance of typical Chinese style cooking hoods," In Building Simulation, vol. 6, pp. 139-149, 2013.

[14] Gynther, Lea, Irmeli Mikkonen, and Antoinet Smits. "Evaluation of European energy behavioural change programmes." Energy Efficiency, vol. 5, pp. 67-82, 2012.

[15] Directive 2010/30/EU of the European parliament and of the council of 19 May 2010 on the indication by labelling and standard product information of the consumption of energy and other resources by energy-related products.

[16] Directive 2009/125/EC of the European Parliament and of the Council of 21 October 2009 establishing a framework for the setting of ecodesign requirements for energy-related products.

[17] The International Electrotechnical Commission (IEC), "Household range hoods - Methods for measuring performance", IEC 61591, 2005.

[18] The International Electrotechnical Commission (IEC), "Household and similar electrical appliances - Test code for the determination of airborne noise - Part 1: General requirements", IEC 60704-1, 2010. 
[19] M. Pinelli, A. Suman, "A numerical method for the efficient design of free opening hoods in industrial and domestic applications," Energy, vol. 74, pp. 484-493, 2014.

[20] M.M. Lunden, W.W. Delp, B.C. Singer, "Capture efficiency of cooking-related fine and ultrafine particles by residential exhaust hoods," Indoor Air, vol. 25, pp. 45-58, 2015.

[21] E. Nas, B. Öztürk, "Optimization of surface roughness via the Taguchi method and investigation of energy consumption when milling spheroidal graphite cast iron materials," Materials Testing, vol. 60(5), pp. 519-525, 2018.

[22] T. Kivak, "Optimization of surface roughness and flank wear using the Taguchi method in milling of Hadfield steel with PVD and CVD coated inserts," Measurement, vol. 50, pp. 19-28, 2014.

[23] K. Aslantaş, E. Ekici, A. Çiçek, "Optimization of process parameters for micro milling of Ti-6Al4V alloy using Taguchi-based gray relational analysis," Measurement, vol. 128, pp. 419-427, 2018.

[24] B. Özlü, M. Akgün, H. Demir, "AA6061 Alaşımının Tornalanmasında Kesme Parametrelerinin Yüzey Pürüzlülügü Üzerine Etkisinin Analizi ve Optimizasyonu,“ Gazi Mühendislik Bilimleri Dergisi, vol. 5(2) pp. 151-158, 2019.

[25] P.J. Ross, “Taguchi Techniques for Quality Engineering,” Mc Graw-Hill, New York, USA, 1996.

[26] M.S. Phadke, "Quality Engineering Using Robust Design,” Printice Hall, Englewood Cliffs, NJ, 1989.

[27] H. Akkuş ve H. Yaka, "Optimization of Turning Process By Using Taguchi Method," Sakarya Üniversitesi Fen Bilimleri Enstitüsü Dergisi, vol. 22(5), pp. 1444-1448, 2018.

[28] E. Nas and H. Gökkaya, "Experimental and statistical study on machinability of the composite materials with metal matrix Al/B4C/Graphite," Metallurgical and Materials Transactions A, vol. 48, pp. 5059-5067, 2017.

[29] A.P. Paiva, J.H.F. Gomes, R.S. Peruchi, R.C. Leme and P.P. Balestrassi, "A multivariate robust parameter optimization approach based on principal component analysis with combined arrays," Comput Ind Eng, Elsevier, vol. 74, pp.186-198, 2014. 